\title{
Proximate Chemical Composition and Antimicrobial Activities of Fixed oils from Diospyros lotus L.
}

\section{Ghias Uddin ${ }^{1}$, Abdur Rauf ${ }^{1 *}$, Bina Shaheen Siddiqui ${ }^{2}$, Mohammad Arfan ${ }^{1}$, Inayat-Ur-Rahman ${ }^{3}$ and Inamullah Khan ${ }^{4}$}

${ }^{1}$ Institute of Chemical Sciences, University of Peshawar, Peshawar, KPK, Pakistan

${ }^{2}$ H.E.J. Research Institute of Chemistry, International Center for Chemical and Biological Sciences, University of Karachi, Karachi-75270, Pakistan

${ }^{3}$ Medicinal Botanic Centre PCSIR Laboratories Complex Peshawar, Peshawar, KPK, Pakistan

${ }^{4}$ Department of Pharmacy, University of Peshawar, Peshawar, KPK, Pakistan

\begin{abstract}
Diospyros lotus roots are traditionally used in various diseases including its use in microbial infections. We designed a study to identify chemical constituents of oil from $D$. lotus and its antimicrobial activities. Gas chromatography coupled to mass spectrometer (GC-MS) was used for chemical analyses. Results showed that oil contained saturated as well as unsaturated compounds. Oil was investigated for its antimicrobial properties. Oil showed moderate antibacterial activity against two gram positive and two gram negative bacterial strains however oil showed low activity against four fungal strains. Interestingly no cytotoxicity was observed in Brine shrimp model; these encouraging results indicate further yet extensive studies to explore therapeutic potential in microbial infections.
\end{abstract}

Keywords: Diospyros lotus; Antibacterial; Antifungal

\section{Introduction}

Diospyros lotus belongs to family Ebenaceae, which consists of about 500 species. Genus Diospyros is widely distributed in tropical and subtropical region throughout world. Characteristic feature of Diospyros species is that all members of the genus are trees [1]. D. lotus tree grows up to $9 \mathrm{~m}$ in height and around $6 \mathrm{~m}$ in width. This plant is rarely available in Britain and it is native to Himalayan region. In folk medicine, Diospyros species are known for their multiple medicinal uses. In many traditional and folk medicinal systems all over the world, Diospyros plants are well known for their medicinal and therapeutic value. All parts of these plants have been used for medicinal purposes e.g. the leaves are used for lumbago; the fruits are carminative, astringent and cure biliousness the seeds are sedative and the bark is bitter, astringent and febrifuge [2]. Leaf extract of Japanese persimmon D. kaki in combination with jasmine is used in Japan for making antitobacco smoking candies. Triterpenoids belonging to lupane, oleanane and ursane series have been isolated and showed anti-inflammatory activity [3]. Diospyros species are used in folk medicinal systems for various medicinal uses such as their use used as antifungal for internal hemorrhage, for bedwetting in children, Woman's drug for insomnia hiccough, as an antihypertensive, dysponea, vermicide and vermifuge, sedative, antifebrile, to promote secretions, astringent, bactericidal $[4,5]$. There are only a few reports on the studies of the roots of this plant $[6,7]$ hence in the current study we have made an effort to analyze the chemical constituents of this part and evaluate its antimicrobial and cytotoxicity activity.

\section{Material and Methods}

\section{Plant material}

D. lotus roots were collected from Razagram, Toormang distic Dir Khyber Pakhtunkhwa (KPK) province of Pakistan in the month of august, 2009. The plant was identified by Prof. Dr. Abdur Rahsid, Department of Botany, University of Peshawar, Peshawar, KPK, Pakistan and a Voucher specimen No Rauf (6645) [8] was deposited at the herbarium of the said department.

\section{Extraction of oil}

Shade dried and crushed roots of $D$. lotus $(14 \mathrm{~kg})$ were subjected to cold extraction with $\mathrm{MeOH}(3 \times 10 \mathrm{~L})$ at room temperature. Extract was then concentrated under reduced pressure at temperature below $55^{\circ} \mathrm{C}$. Final residue obtained was $400 \mathrm{~g}$. This methanolic extract was suspended in water and successively partitioned with hexane, chloroform, EtOAc. Hexane fraction ( $8 \mathrm{~g}$ ) was subjected to Column chromatography on silica gel (Merck, $5 \times 60 \mathrm{~cm}$ ). Column was eluted with hexane/EtOAc $(100: 0 \rightarrow 0: 10)$ as solvent system. A total of 30 fractions, RF-1 to RF30 were obtained based on TLC profiles. Fraction RF-10 to RF-13 contained yellow colored oil. Extracted oil was subjected GC-MS analysis and injected $1 \mu \mathrm{l}$ to GCMS using auto injector system.

\section{Chemicals and reagents for GC-MS}

Boron triflouride solution in methanol (10\%) was purchased from Fluka Chemie (Buchs, Switzerland). Sodium hydroxide solution (methanolic; $0.5 \mathrm{~N}$ ) and sodium chloride (analytical grade) were obtained from Merck (Darmstadt, Germany) while methanol (HPLC grade), $n$-hexane (HPLC grade) were from Fischer Scientific (Leicestershire, UK). Helium gas (99.9999\%) from Pak gas (United Arab Emirates) was procured. Tridecanoic acid methyl ester and Fatty acid methyl esters (FAMEs) having 37 components (Table 1) standard mixture were obtained from AccuStandard (Newhaven, Connecticut USA).

\section{Preparation of standard for GC-MS}

Internal standard was prepared by dissolving $13.7 \mathrm{mg}$ of tridecanoic acid methyl ester in $1 \mathrm{~mL}$ hexane. External standard was prepared by diluting $10 \mathrm{mg}$ of 37 component FAMEs mix standard to $10 \mathrm{~mL}$ with dichloromethane. From this solution further working standard solutions were prepared.

*Corresponding author: Abdur Rauf, Institute of Chemical Sciences, University of Peshawar, Peshawar, KPK, Pakistan, Tel: +923469488944; E-mail: mashaljcs@yahoo.com; mashalics@gmail.com

Received August 16, 2013; Accepted November 06, 2013; Published November 08, 2013

Citation: Uddin G, Rauf A, Siddiqui BS, Arfan M, Rahman IU, et al. (2013) Proximate Chemical Composition and Antimicrobial Activities of Fixed oils from Diospyros lotus L. Med chem 3: 282-285. doi:10.4172/2161-0444.1000152

Copyright: $\odot 2013$ Uddin G, et al. This is an open-access article distributed under the terms of the Creative Commons Attribution License, which permits unrestricted use, distribution, and reproduction in any medium, provided the original author and source are credited. 


\begin{tabular}{|c|c|c|c|c|c|}
\hline ID\# & Name & R. Time & Area & Conc. (\%) & Std. Dev. \\
\hline 1 & C6:0; Hexanoic acid, methyl ester & 3.028 & 2637 & 40.00 & 0.001 \\
\hline 2 & C8:0; Caprylic acid, methyl ester & 4.911 & 43548 & 40.00 & 0.002 \\
\hline 3 & C10:0; Capric acid, methyl ester & 6.743 & 59804 & 40.00 & 0.002 \\
\hline 4 & C11:0; Undecanoic acid, methyl ester & 7.608 & 32300 & 20.00 & 0.003 \\
\hline 5 & C12:0; Lauric acid, methyl ester & 8.493 & 67697 & 40.00 & 0.002 \\
\hline 6 & C13:0; Tridecanoic acid, methyl ester & 9.554 & 35734 & 20.00 & 0.003 \\
\hline 7 & C14:0; Myristic acid, methyl ester & 10.897 & 72212 & 40.00 & 0.003 \\
\hline 8 & C14:1c; Myristoleic acid, methyl ester & 11.466 & 8237 & 20.00 & 0.003 \\
\hline 9 & C15:0; Pentadecanoic acid, methyl ester & 12.548 & 38432 & 20.00 & 0.003 \\
\hline 10 & C15:1; Pentdecanoic acid, methyl ester & 13.234 & 7517 & 20.00 & 0.002 \\
\hline 11 & C16:0; Palmitic acid, methyl ester & 14.533 & 118819 & 60.00 & 0.002 \\
\hline 12 & C16:1c; Palmitoleic acid, methyl ester & 15.066 & 7253 & 20.00 & 0.002 \\
\hline 13 & C17:0; Margaric acid, methyl ester & 16.829 & 34317 & 20.00 & 0.003 \\
\hline 14 & C17:1; Heptadecenoic acid, methyl ester & 17.417 & 7643 & 20.00 & 0.003 \\
\hline 15 & C18:0; Stearic acid, methyl ester & 19.500 & 67063 & 40.00 & 0.001 \\
\hline 16 & C18:1c; Oleic acid, methyl ester & 20.038 & 17841 & 40.00 & 0.003 \\
\hline 17 & C18:1n9T; Elaidic acid, methyl ester & 20.115 & 7232 & 20.00 & 0.003 \\
\hline 18 & C18:2T; Linoleic acid, methyl ester & 21.608 & 8777 & 20.00 & 0.004 \\
\hline 19 & C18:2C; Octadecadionoic acid, methyl ester & 21.856 & 9261 & 20.00 & 0.001 \\
\hline 20 & C18:3n6; G-linoleic acid, methyl ester & 22.762 & 5708 & 20.00 & 0.002 \\
\hline 21 & C18:3n3; Linolenic acid, methyl ester & 24.160 & 6455 & 20.00 & 0.003 \\
\hline 22 & C20:0; Arachidic acid, methyl ester & 27.058 & 66297 & 40.00 & 0.004 \\
\hline 23 & C20:1; Eicosenoic acid, methyl ester & 27.659 & 8757 & 20.00 & 0.003 \\
\hline 24 & C20:2; Eicosadienoic acid, methyl ester & 29.395 & 6480 & 20.00 & 0.002 \\
\hline 25 & C20:3n6; 8,11,14-Eicosatrienoic acid, methyl ester & 30.312 & 6128 & 20.00 & 0.004 \\
\hline 26 & C21:0; Heneicosanoic acid, methyl ester & 30.745 & 30613 & 20.00 & 0.004 \\
\hline 27 & C20:4n6; Arachidonic acid, methyl ester & 31.073 & 5846 & 20.00 & 0.003 \\
\hline 28 & C20:3n3; Eicosatrienoic acid, methyl ester & 31.717 & 9586 & 20.00 & 0.001 \\
\hline 29 & C20:5N3; (EPA) Eicosapentaenoic acid, methyl ester & 33.359 & 6262 & 20.00 & 0.001 \\
\hline 30 & C22:0; Behenic acid methyl ester & 34.188 & 62867 & 40.00 & 0.005 \\
\hline 31 & C22:1; Eruccic acid methyl ester & 34.753 & 6847 & 20.00 & 0.001 \\
\hline 32 & C22:2; Locosadienoic acid, methyl ester & 36.323 & 9365 & 20.00 & 0.002 \\
\hline 33 & C23:0; Tricosanoic acid methyl ester & 37.440 & 29002 & 20.00 & 0.002 \\
\hline 34 & C24:0; Tetracosanoic acid methyl ester & 40.521 & 60828 & 40.00 & 0.003 \\
\hline 35 & C22:6n3; (DHA) Docosahexaenoic acid, methyl ester & 40.859 & 5333 & 20.00 & 0.002 \\
\hline 36 & C24:1; Tetracosenoic acid methyl ester & 41.098 & 9144 & 20.00 & 0.002 \\
\hline
\end{tabular}

Table 1: Quantification results of 37 components standard.

\section{Chromatographic separation of FAMEs}

A gas chromatograph from Shimadzu hyphenated to a mass spectrometer QP 2010 plus (Tokyo, Japan) equipped with an autosampler (AOC-20S) and auto-injector (AOC-20i) was used. Helium was used as carrier gas. All chromatographic separations were performed on a capillary column (TRB-FFAP; Technokroma) having specifications: length; $30 \mathrm{~m}$, id.; $0.35 \mathrm{~mm}$, thickness; $0.250 \mu \mathrm{m}$, treated with polyethylene glycol. Other GC-MS conditions are: ion source temperature (EI): $250^{\circ} \mathrm{C}$, interface temperature: $240^{\circ} \mathrm{C}$, pressure: 100 $\mathrm{KPa}$, solvent cut time; $1.6 \mathrm{~min} .1 \mu \mathrm{L}$ of sample and standard were injected into the GC column. Injector was operated in a split mode with a split ratio $1: 50$. Injection temperature was $240^{\circ} \mathrm{C}$. The column temperature program started at $50^{\circ} \mathrm{C}$ for $1 \mathrm{~min}$ and changed to $150^{\circ} \mathrm{C}$ at the rate of $15^{\circ} \mathrm{C} / \mathrm{min}$. The temperature was raised to $175^{\circ} \mathrm{C}$ at the rate of $2.5^{\circ} \mathrm{C} / \mathrm{min}$ and held for 5 minutes. Then the temperature was increased to $220^{\circ} \mathrm{C}$ at the rate of $2.5^{\circ} \mathrm{C} / \mathrm{min}$ and kept constant for 5 minutes. Total elution time was 45 minutes. MS scanning was performed from $\mathrm{m} / z 85$ to $m / z 380$. GC-MS solutions software provided by the supplier was used to control the system and to acquire the data. Identification of the compounds was carried out by comparing the mass spectra obtained with those of standard mass spectra from the NIST library (NIST 05).

\section{Antimicrobial activities}

In this study six fungal and five bacterial strains were used as reported earlier $[9,10]$. Bacterial strains used were Escherrchia coli, Bacilus subtilis, Staphylococcus aureus, Klebsiella pneumonia and Straptococcus epidermis. Fungal strains chosen for this study were Trichophyton longifusus, Candida albicans, Aspergillus flavus, Microspoum canis, Fusarium salani and Candida glaberata. All these strains were maintained on agar slant at $4^{\circ} \mathrm{C}$. Slant was allowed to activate at $37^{\circ} \mathrm{C}$ for 24 hours on Müller-Hinton agar (for bacteria) and Sabouraud glucose agar (fungi) before any screening. Cultures were taken in triplicates at incubation temperature of $37^{\circ} \mathrm{C}$ for 24 to 72 hours. Broth culture $(0.6 \mathrm{~mL})$ of the test organism was placed in a sterile Petri-dish to which $20 \mathrm{ml}$ of the sterile molten MHA was added. Holes were bored in to the medium using $0.2 \mathrm{ml}$ of the oil. Streptomycin was the standard antimicrobial agent at a concentration of $2 \mathrm{mg} / \mathrm{ml}$. Inoculation was done for $1 \mathrm{~h}$ to make possible the diffusion of the antimicrobial agent into the medium. Incubation was done at $37^{\circ} \mathrm{C}$ for $24 \mathrm{~h}$ and the diameters of the zone of inhibition of microbial growth were measured in the plate in millimeters. Extent of antimicrobial activity was obtained by measuring the diameter of zone of inhibition around the hole. Bioassay was repeated three times and then the mean diameter was determined. In this study streptomycin, miconazole and 


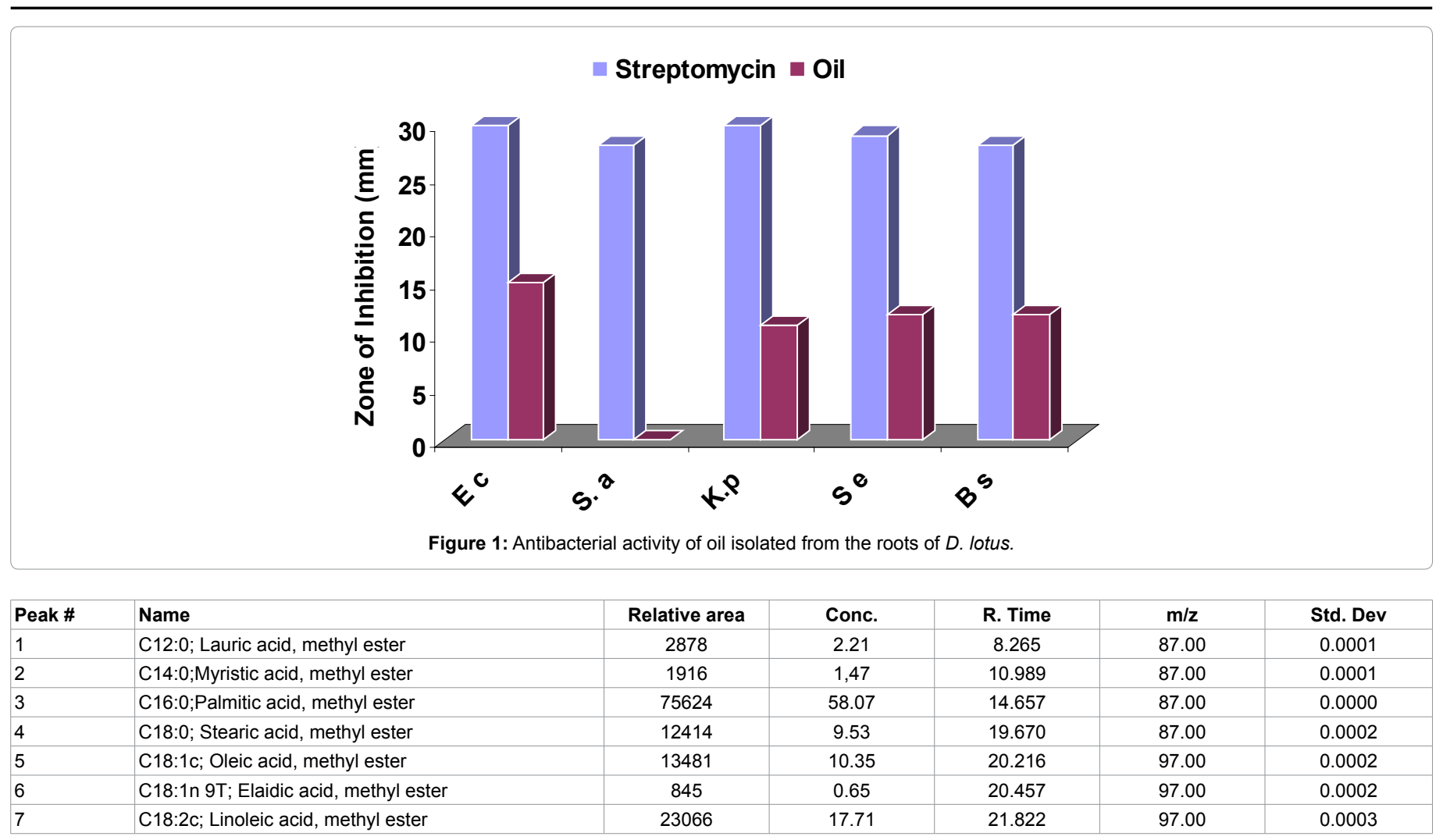

Table 2: Quantification results of fixed oil isolated from $D$. lotus roots.

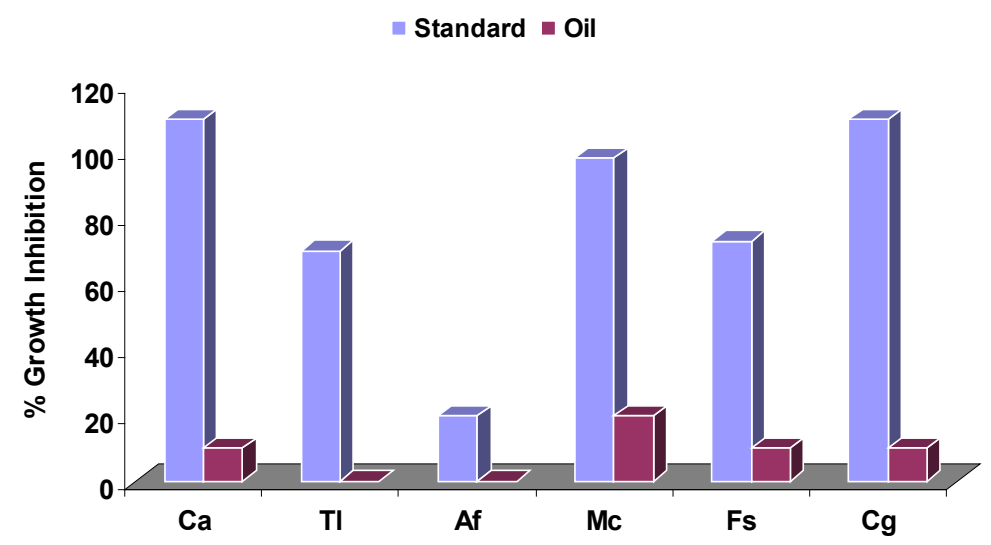

Quantification results of fixed oil isolated from $D$. lotus roots

Figure 2: Antifungal activity of oil isolated from the roots of $D$. lotus.

amphotericin B were used as standard antibiotics to compare extract and fraction with it.

\section{Cytotoxicity activity}

A shallow rectangular plastic dish $(22 \times 32 \mathrm{~cm})$, filled with artificial sea water was taken. The sea water was prepared with commercial salt mixture mixed with double distilled water. Brine shrimp (Artemia salina leach) eggs were hatched the dish. Dish was made unequally partitioned by using an artificial perforated device. About $50 \mathrm{mg}$ of the eggs were sprinkled in to large compartment which becomes darken. Minor compartment was exposed to the ordinary light. After two days, nauplii were collected and removed by a pipette from lighted side. A sample of the compounds to be tested was prepared by dissolving 20 $\mathrm{mg}$ of each compound in DMF (2 ml). Three different stock solution i.e., 550,50 , and $5 \mathrm{mg} / \mathrm{mL}$ were transferred to 9 vials (three for every dilution were used for each test sample and $\mathrm{LD}_{50}$ is the average of the three values) with one vial containing DMF was reserved as a control. Solvent was allowed to evaporate keeping overnight. Two days, later when the shrimp larvae were ready, $1 \mathrm{~mL}$ of sea water and 10 shrimp were added to each vial (30 shrimps/ dilution) with a volume adjusted with sea water to $5 \mathrm{~mL}$ per vial. After $24 \mathrm{~h}$, the numbers of survivors were counted using standard procedure [11-13]. The data was analyzed by the use of finny computer program to determine $\mathrm{LD}_{50}$ values (Figure $1)$. 
Citation: Uddin G, Rauf A, Siddiqui BS, Arfan M, Rahman IU, et al. (2013) Proximate Chemical Composition and Antimicrobial Activities of Fixed oils from Diospyros lotus L. Med chem 3: 282-285. doi:10.4172/2161-0444.1000152

\section{Results and Discussion}

\section{GC-MS analysis}

Table 2 presents the results obtained from GC-MS analysis indicating relative concentration of individual FAMEs based on the external standard method. Analysis was repeated three times and values of area and concentration are given in Table 2. Quantification of FAMEs was performed using three points calibration curve with $\mathrm{R} 2$ value less than $0.99\left(\mathrm{R}^{2}>0.99\right)$ in each case. Table 2 shows the Quantification results obtained from fatty acid standard mixture of 37 components while Table 1 is the GC-MS chromatogram of $D$. lotus roots oil with properly labeled signals of analytes detected (Figure 2).

Both the saturated and unsaturated FAMEs were detected in sample under investigations. Palmitic acid, methyl ester was found in highest concentration (58.07\%) among the identified analyzes of interest which shows anti-inflammatory and antibacterial activities. Second FAME with higher concentration was Linoleic acid methyl ester (17.71\%). Among the other FAMES with concentrations more than $1 \%$ were: Oleic acid, methyl ester (10.35\%), Stearic acid, methyl ester (9.53\%), Lauric acid, methyl ester (2.21\%) and Myristic acid, methyl ester $(1.47 \%)$ were found. Concentrations of Llaidic acid methyl ester were less than $1 \%$ (Table1). Fixed oil revealed moderate antibacterial activity against all test bacterial strain except Staphylococcus aureus and E. coli was found to be the most susceptible bacterial strain. However streptomycin (standard) exhibited comparatively better activity than oil. In case of antifungal activity, only low activities were observed against. Candida albicans, Aspergillus flavus, Microspoum canis, Fusarium salani and Candida glaberata. Interestingly oil showed no considerable toxicity in brine-shrimp lethality assay which indicates safety of oils for pharmacological use. This study highlighted potential of $D$. lotus to be investigated further for its antibacterial effects at cellular and molecular levels.

\section{References}

1. Uddin G, Rehman TU, Arfan M, Liaqat W, Waliullah, et al. (2011) Antimicrobial, insecticidal and phytotoxic activities of Indigofera heterantha roots. J Med Plants Res 5: 5835-5839.

2. Pant S, Samant SS (2010) Ethanobotanical observation in the Momaula Reserve Forest of KoumounWest Himalaya, India. Ethnobotanical Leaflets 1493.

3. Watt JM, Breyer-Brandwijk MG (1932) The Medicinal and Poisonous Plants of South Africa. Postgrad Med J 8: 427.

4. Tezuka M, Takahashi C, Kuroyanagi M, Satake M, Yoshihira K, et al. (1973) New naphthoquinones from Diospyros. Phytochemistry 12: 175-183.

5. Thomas PS, Karagianis G, Brun R (2006) Phytochemistry 67:1950-1957.

6. Yoshihira K, Tezuka M, Natori S (1970) Napthoquinone derivatives from Diospyros SPP.: bisisodiospyrin, a tetrameric napthoquinone. Tetrahedran Lett 11: 7-10.

7. Uddin G, Rauf A, Arfan M, waliullah, Rehman TU, et al. (2013) Molecular docking of Diospyrin as a LOX inhibitory compound. J Saudi Chem.

8. Rauf A, Muhammad N, Khan A, Uddin N, Atif M, et al. (2012) Antibacterial and Phytotoxic Profile of Selected Pakistani Medicinal Plants. World Applied Sci J 20: $540-544$

9. Uddin G, Rauf A, Bina SS, Shah SQ (2011) Preliminary comparative phytochemical screening of Diospyros lotus Stewart. Middle-East J Sci Res 7: 707-711.

10. Uddin G, Rauf A, Qaisar M, Latif A, Ali M (2011) Preliminary Phytochemica Screening and Antimicrobial Activity of Hedera helix L. Middle-East J Sci Res 8: 198-202.

11. Uddin G, Rauf A (2012) Phytochemical screening and biological activity of the aerial parts of Elaeagnus umbellate. Sci Res Essays 7: 3690-3694.

12. Bashir AK, Abdalla AA, Wasfi IA, Hassan ES, Amiri MH, et al. (1994) Flavonoids of Limonium axillare. Int J Pharmacogn 32: 366-372.

13. Yadava RN, Jain S (2005) A new bioactive flavone glycoside from the seeds of Melilotus indica All. J Asian Nat Prod Res 7: 595-599. 